\title{
Curriculum And Studies In Enhancing The Understanding Of Mathematical Concepts On Elementary School Students
}

\author{
R.Sri Martini Meilanie, Yasmin Faradiba, Sulfikar Sallu
}

\begin{abstract}
The two horrible conditions ahead of time than the organizers worldwide are to diminish the stack at the conventional fills and to reduce the continually developing basic spoiling. This test is proposed to discover probably the execution of the DI diesel motor at various loads when fuelled with mixes of palm methyl esters and diesel. The primers have been pushed on a completely utilized diesel motor without changes. Every one of the appraisals were consistent usa of america and outfitted toward dependable pace. The impact of moving weight develop to be assessed the volume that brake warm temperature ability, mass flow rate, brake one of a kind gas use and fumes gas temperature. Exploratory impacts show that at complete weight conditions, the B-20, B-40and B-60 mixes bring 33.23\%, 32.81\%, $32.39 \%$ and 31.ninety seven\% higher brake heat usefulness than sole diesel freely. It wound up confirmed that the brake warmth ability of palm biodiesel is higher than that of diesel, and it is a delayed consequence of the oxygenated atom of biodiesel which acknowledges total ingesting of the biodiesel fuel. In addition the mass development rate of biodiesel is evidently superior to anything that of diesel fuel; it is through method for exact capacity of the calorific estimation of biodiesel is a ton parcels less appeared in one another way as far as diesel gas. At the reason for results obtained from this test utilizing palm biodiesel as a fuel is proposed for the utilized as a piece of a diesel motor with diesel mixes.
\end{abstract}

Keywords: biodiesel, esterification, pyrolysis, emulsification, blends.

\section{INTRODUCTION}

In providing knowledge to children, education and learning (1) (2)are not only preparing children to be smart in terms of their knowledge. But also, it is supposed to make children be more mature in attitudes and behaviors (3) (4). Children understand positive values that underlie moral attitudes (5) and behaviors based (6) on knowledge they get from their interaction in environment. Maturity of children's attitudes and behaviors in interacting with the environment can be learned (7) through concept-based science learning with exploration, discovery $(8,9)$ and inquiry learning approaches (10-12) . Because learning science must understand the basic concepts of science and be taught with the approach of exploration, discovery and inquiry learning Learning science for early childhood is as an introduction, so that in the learning process so that children have the

Revised Manuscript Received on April 19, 2019.

R.Sri Martini Meilanie, Teacher education, early childhood education, Universitas Negeri Jakarta, Indonesia

Yasmin Faradiba, Teacher education, early childhood education, Universitas Negeri Jakarta, Indonesia Sembilanbelas November, Kolala Sulawesi Tenggara, Indonesia
Sulfikar Sallu, Faculty of Information Technology, Universitas

provision of understanding and knowledge then learning must be introduced to the basic concepts correctly to enrich them with good learning experience. This learning experience will be brought by the child when entering advanced education (13), for example such question "why does the form of water change and follow the place where the water is located". The children will continue to ask the question until they find different forms (14-17) of water and the content or volume remains the same. This is the discovery activity carried out by children in learning, where children study and find answers to "why this and why so" for the question and curiosity of the child. Blended Learning Technology can employ all media as a teaching and learning aids covering text, sound, still images, moving images, videos, animation and others that will change the child's mindset about the subject in question. Concept-based science learning is a learning process that must be carried out (18) by the teacher so that the child has an understanding of simple science concepts that are the provision for following learning at the next level. These are the competencies that children must have to take part in more complex science learning $(19,20)$. Teachers believe that children have great curiosity. This great child's curiosity must continue to be stimulated until he or she has an understanding and answers about what he or she wants to know. This child's curiosity must have the right scientific foundation. This foundation can be a provision for children to learn science at the next level. Therefore, science learning must be done until children understand and master the basic concepts of science that are taught, so that children are rich in basic concepts of simple science that must be understood and mastered.

\section{LITERATURE REVIEW}

The concept of curiosity of child must be stimulated continually (21-24). The basic concepts of simple science can be done by children in learning activities individually or in groups (25-27) in the classroom under the guidance of teachers or independently through demonstration activities(28) and other evidentiary activities. Children's knowledge needs to be owned early on (29-31). To record all events experienced through the process of education and learning that is good and right. Blended Learning can be used as one of the tools in the learning process in the classroom. 


\section{METHODOLOGY / MATERIALS}

In the implementation of science education and learning activities, the teacher must understand the basic concepts of the material to be taught, so that science learning is not only based on activities without a meaning and understanding of the basic concepts that occur. For example making sweet tea, making donuts, making fruit satay is an introduction to science without attaching the concept behind making sweet tea, donuts and fruit satay. At this learning stage, the teacher is expected to master the simple concepts of science learning that are introduced to children. The learning process uses the exploration approach, discovery and inquiry learning because in early childhood learning activities are expected to be carried out based on interests, needs continuously so that children can comprehend quickly and correctly the learning materials, because learning comes from children interest. The last stage is inquiry learning, which is the stage of activities carried out by children to find and multiply further until the child gets a belief in the question and curiosity. The answers found at this stage are usually highly believed by the child and are used as the basis of the concept of knowledge. Since learning for early childhood whose understanding has not been formed optimally, teacher is required to be able to stimulate the child curiosity until he or she has the desire to seek answers of his or her curiosity.

The stages of the use of concept-based science learning models with the exploration approach, discovery and designed inquiry learning are described as follows:

\section{First Stage: Preparation}

In this first stage, the teacher prepares the material to be taught, the learning objectives to be achieved are indicators of complete learning achievement which will be used as children's competencies, activities to be carried out by children, learning media and evaluation of the process and results of learning. Learning activities are complemented by experimental steps and demonstrations that will be carried out by the child together with the teacher or independently. For the independent assignment, the teacher makes a guidebook for the activities that will be carried out individually or in groups by the children, so that the steps to be taken by the child in accordance with scientific concepts will be studied.

\section{Second Stage: Orientation}

Before the actual learning activities are carried out, the teacher and the child conduct an apperception of the material that has been taught with examples of activities and events around the child that are useful for reminding what has been learned and what has to do with the material to be studied, so that children's understanding can be arranged well through these simple examples.

\section{Third Stage: Presentation}

In the second stage, the teacher and child are already in the learning process. The teacher begins the learning process by conveying new concepts or skills that the child will have as their competences. Then, the teacher gives an illustration or examples in the form of visual or assignments. Lastly, the teacher evaluates the child's understanding of the instructions given in order to dissect the material so that the child understands more.

\section{Fourth Stage: Structured practice}

For the third stage the teacher has begun to guide the child per group to practice the examples planned by the teacher and become the learning goals that the child must achieve (the competencies that the child will achieve). The teacher hopes that children will respond with attitudes and behaviors that are in accordance with the indicators / sub indicators that will be achieved by the child. If the child does not understand well, the child can respond with questions so that the teacher can re-explain the target learning objectives to be achieved. The third stage was closed with the teacher providing corrections and directives on mistakes or errors made by the child during the trial and demonstration and other proofs, so that the pattern of behavior as a form of mindset can be formed optimally.

\section{Fifth Stage: Practice under Teacher Guidance}

In the fourth stage, the teacher give instructions in the form of drawings / examples of activities even experimental assignments, observing simple basic concepts of science. Furthermore, children are asked to practice the basic concepts according to the teacher's instructions in a semiindependent manner. This step is carried out in turns both groups and individuals. In this fourth stage, children are invited to observe examples of science concepts, behavior patterns of friends who are instructed by the teacher and analyze and respond in the form of criticism and suggestions for the form of behavior patterns that will characterize the child. The fifth stage is closed by the teacher by providing feedback on the behavior movements produced by the child in order to form the requested character according to the planned indicators / sub indicators.

\section{Sixth Stage: Independent Practice}

At this stage, it is expected that the child's understanding is more mature, so that the child can immediately receive and understand the instructions given by the teacher. At this stage the child takes direct practice independently both at school and at home. The teacher cooperates with parents to observe to evaluate children's understanding of the basic concepts of science that must be understood by children, see the emergence of curiosity of children and the formation of patterns of behavior as a form of scientific mindset in children. This independent practice is carried out repeatedly and continuously and continuously in a long enough period so that the pattern of behavior that embodies the child's scientific mindset is formed optimally.

By conducting learning activities involving students, it is hoped that this learning activity can attract children's attention, so that learning activities can stimulate the curiosity of other group members

\section{RESULTS AND FINDINGS}

With the condition of the child's interest is quite large, usually the child's thinking will continue to work looking 
for, fulfilling his or her great curiosity until the child feels he or she gets an answer to the curiosity. This is the exploration process that children undergo, so that in the child's mind the question "why is this, why is that" will appear. Furthermore, after the child finds out about what is being questioned in his or her mind, the child will continue to study more deeply and more fully about the problems found during his or her exploration activities.

Figure 1. Blended Learning Technology

Blended learning presents a combination of existing technologies with the capabilities so that someone will have new knowledge. This is very suitable for those who are in the process of growth and development.

In the end, the concept-based science learning model with exploration, discovery and inquiry learning approaches can provide the understanding and mastery of the basic concepts of science in early childhood that can be used in the next level of education and learning.

The results score used with a qualitative approach can be an indication of

Criteria / Assessment Rubric:

\section{Not developed (BB):}

If the child has not been able to show at all showing attitudes and behavioral curiosity so they do not want or refuse to be involved in learning activities guided by the teacher in small groups.

\section{Start Development $(M B)$ :}

If the child has begun to show attitudes and curiosity towards activities carried out by friends in the group under the guidance of the teacher, and begin to be involved in group activities and can say or state the conditions that exist and experience the child even though still have to be helped and reminded by the teacher.

\section{Developing Hope (BSH):}

If the child is independent and not too much assisted by the teacher, the child can understand and master the material taught and the activities carried out and can tell / express what he sees, feels and understands well.

\section{Excellent Development (BSH):}

If the child has independently carried out all activities without asking for help from the teacher, he or she can carry out learning activities with experiments, demonstrations and other evidentiary activities in the class properly and correctly without having to be guided and he or she can tell / express what is felt, seen and found while learning activities both spontaneously and with memories needed in an open, detailed and full of confidence in the truth.

And the result turns out to be:

1. The teacher does not understand the curriculum and the process of learning mathematics

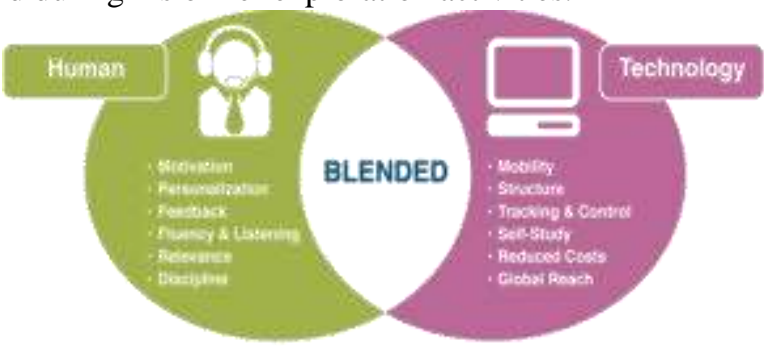

2. The teacher is less creative in choosing the right learning media with the material to be taught

3. The teacher lacks understanding in preparing the Learning Plan

4. The learning plan used by the teacher is the RPP that has been made and sold

5. The learning process of mathematics given by the teacher is only a form of memorizing the stages of solving the problem rather than that it adopts the formula

6. The learning process carried out by students is less meaningful

7. Teachers lack understanding of blended learning

8. School facilities do not allow for learning "blended learning"

9. The learning process is always done paperless

10. Teachers have never done learning with problem solving

11. Teachers still has lack of understanding on IT

\section{CONCLUSION}

Some information are obtained in this study namely: The teacher does not understand the curriculum and the learning process of mathematics, the learning process is less meaningful because only memorizing the stages of problem solving. The teacher understanding on IT is also less. Teacher's creativity is less in choosing learning media, School learning " blended learning" cannot be fulfilled. And the available curriculums make teachers have less motivation in developing learning plan

\section{ACKNOWLEDGMENT}

\section{REFERENCES}

1. Viberg O, Hatakka M, Bälter O, Mavroudi A. The current landscape of learning analytics in higher education. Computers in Human Behavior. 2018;89:98110.

2. Pappas IO, Giannakos MN, Sampson DG. Fuzzy set analysis as a means to understand users of 21 st-century learning systems: The case of mobile learning and reflections on learning analytics research. Computers in Human Behavior. 2019;92:646-59.

3. Josephs M, Kushnir T, Grafenhain M, Rakoczy H. Children protest moral and conventional violations more when they believe actions are freely chosen. J Exp Child Psychol. 2016;141:247-55.

4. Karine Charry BP. Children's response to "ecofriendly" labeling: The role of self-concept clarity. Journal of Environmental Psychology. 2018.

5. Benish-Weisman M, Daniel E, Sneddon J, Lee J. The relations between values and prosocial behavior among children: The moderating role of age. Personality and Individual Differences. 2019;141:241-7.

6. Prabhakar J, Weisberg DS, Leslie AM. The interplay between moral actions and moral judgments in children and adults. Conscious Cogn. 2018;63:183-97.

7. Acar H. Learning Environments for Children in Outdoor Spaces. Procedia - Social and Behavioral Sciences. 2014;141:846-53.

8. Metcalf SJ, Reilly JM, Kamarainen AM, King J, Grotzer TA, Dede C. Supports for deeper learning of inquiry- 
based ecosystem science in virtual environments Comparing virtual and physical concept mapping. Computers in Human Behavior. 2018;87:459-69.

9. Hardy JH, Day EA, Arthur W. Exploration-exploitation tradeoffs and information-knowledge gaps in selfregulated learning: Implications for learner-controlled training and development. Human Resource Management Review. 2019;29(2):196-217.

10. Theobald KA, Ramsbotham J. Inquiry-based learning and clinical reasoning scaffolds: An action research project to support undergraduate students' learning to 'think like a nurse'. Nurse Educ Pract. 2019;38:59-65.

11. Xing W, Popov V, Zhu G, Horwitz P, McIntyre C. The effects of transformative and non-transformative discourse on individual performance in collaborativeinquiry learning. Computers in Human Behavior. 2019;98:267-76.

12. Stockdale J, Hughes C, Stronge S, Birch M. Motivating midwifery students to digitalise their enquiry-based learning experiences: An evaluative case study. Studies in Educational Evaluation. 2019;60:59-65.

13. Bers MU, González-González C, Armas-Torres MB. Coding as a playground: Promoting positive learning experiences in childhood classrooms. Computers \& Education. 2019;138:130-45.

14. Ronfard S, Zambrana IM, Hermansen TK, Kelemen D. Question-asking in childhood: A review of the literature and a framework for understanding its development. Developmental Review. 2018;49:101-20.

15. Ensor JE, Wennström P, Bhatterai A, Nightingale AJ, Eriksen S, Sillmann J. Asking the right questions in adaptation research and practice: Seeing beyond climate impacts in rural Nepal. Environmental Science \& Policy. 2019;94:227-36.

16. Mills $\mathrm{CM}$, Legare $\mathrm{CH}$, Grant $\mathrm{MG}$, Landrum $\mathrm{AR}$. Determining who to question, what to ask, and how much information to ask for: the development of inquiry in young children. $\mathbf{J}$ Exp Child Psychol. 2011;110(4):539-60.

17. Ruggeri A, Lombrozo T. Children adapt their questions to achieve efficient search. Cognition. 2015;143:203-16.

18. Lumosi CK, Pahl-Wostl C, Scholz G. Can 'learning spaces' shape transboundary management processes? Evaluating emergent social learning processes in the Zambezi basin. Environmental Science \& Policy. 2019;97:67-77.

19. Salleh KM, Khalid NH, Sulaiman NL, Mohamad MM, Sern LC. Competency of Adult Learners in Learning: Application of the Iceberg Competency Model. Procedia - Social and Behavioral Sciences. 2015;204:326-34.

20. Jack BM, Lin H-s. Warning! Increases in interest without enjoyment may not be trend predictive of genuine interest in learning science. International Journal of Educational Development. 2018;62:136-47.

21. Dai Q. Back-propagation with diversive curiosity: An automatic conversion from search stagnation to exploration. Applied Soft Computing. 2013;13(1):48395.

22. Perren S, Herrmann S, Iljuschin I, Frei D, Körner C, Sticca F. Child-centred educational practice in different early education settings: Associations with professionals' attitudes, self-efficacy, and professional background. Early Childhood Research Quarterly. 2017;38:137-48.

23. Bellefeuille G, Ricks F. Relational inquiry: A child and youth care approach to research. Children and Youth Services Review. 2010;32(10):1235-41

24. Debbie Laffranchini OaF. Child Growth and Dvelopment, Chapter 2: A Childs World: How We Discovered. 2001.

25. Colliver Y, Veraksa N. The aim of the game: A pedagogical tool to support young children's learning through play. Learning, Culture and Social Interaction. 2019;21:296-310.

26. Jeong J, Frye D. Information about informants' knowledge states affects children's predictions of learning and their actual learning. Cognitive Development. 2018;48:203-16.

27. Papavlasopoulou S, Giannakos MN, Jaccheri L. Exploring children's learning experience in constructionism-based coding activities through designbased research. Computers in Human Behavior. 2019.

28. Kale U. Technology valued? Observation and review activities to enhance future teachers' utility value toward technology integration. Computers \& Education. 2018;117:160-74.

29. Birbili M. Children's interests in the early years classroom: Views, practices and challenges. Learning, Culture and Social Interaction. 2018.

30. Maunsell R, Avelino M, Caixeta Alves J, Semenzati G, Lubianca Neto JF, Krumenauer R, et al. Revealing the needs of children with tracheostomies. Eur Ann Otorhinolaryngol Head Neck Dis. 2018;135(5S):S93-S7.

31. Jones C, Atkinson P, Memon A, Dabydeen L, Das KB, Cross $\mathrm{JH}$, et al. Experiences and needs of parents of young children with active epilepsy: A population-based study. Epilepsy Behav. 2019;90:37-44. 